\title{
ENGG 113 Communications and Design: A First Year Engineering Course at the University of Regina
}

\author{
R. J. Palmer ${ }^{1}$
}

\begin{abstract}
Circa 1990 the Engineering curriculum at the University of Regina was completely overhauled. Previous to this, there were small courses in communication and design. The short courses were combined into a single standard length course of 3 credit hours, ENGG 113, Communications and Design. The underlying principle was that communication was indeed a design process. An essay must be designed, a presentation must be designed and even a sentence must be created using the fundamentals of the design process.

The course incorporates unorthodox practices but it covers a variety of topics that support the design process. For example, time management is not only covered, it is practiced in class by having a student moderate each class. The class is broken into four 17 minute periods, each starting with students doing random self introductions, and ending with student summaries. Student design groups do a presentation during one of these modules. The entire class is under the control of the moderator.

The lab is broken into three sections, a writing activity, a computer activity and a design activity. A design is done, and is presented at the end of the course as a WEB document. This paper describes the topics, the objectives and the methodology of the course and gives an analysis as to what works and what remains lacking.
\end{abstract}

\section{Background}

Before 1990, at the University of Regina, there was a 4/4 delivery system. Most courses were four credit hours, and a full load was considered four courses. After 1990 we switched to 5/3. Five courses were considered a full load, each being three credit hours. This meant that all the courses across campus had to be shortened and new courses developed. At this time in engineering we had a first year design course and a two credit hour communication course. We combined these two courses into a new three credit hour course called ENGG 113, Communications and Design. The author has taught this course since then, and has designed and developed the course.

The combination of design and communication was seen then, and is still deemed a good combination. Communication in a sense is the processes of designing. Synthesizing logical, meaningful sentences and paragraphs is obviously designing. Designing requires good, clear documentation. Teamwork, leadership, and project management require strong communication skills. The message to the students, starting in first year, is that engineering is design and design requires communication.

\section{Course Objectives}

The objectives as given to the class were:

$>$ To develop your communication skills, written \& oral

$>$ To understand and practice the design process

\footnotetext{
${ }^{1}$ Ron Palmer is with Electronic Systems Engineering at the University of Regina, 3737 Wascana Parkway, Regina, Saskatchewan, Canada S4S 0A2 Email: ron.palmer@uregina.ca
} 
To motivate you to be excellent engineers, both as students and as professionals

$>$ To get to know the students in your class

$>$ To learn to work as a team to achieve an objective

$>$ To learn a bit about web page design and WebCT ${ }^{\circledR}$

\section{Marks}

Students are especially keen on knowing exactly how they are to be evaluated. The following was the mark distribution for 2005:

$\begin{array}{lc}\text { Self Introduction } & 4 \\ \text { Computer quiz 8 x 1 } & 8 \\ \text { Final_Computer } & 10 \\ \text { Final_Written } & 10 \\ \text { Mid_Computer } & 10 \\ \text { Mid_Written } & 5 \\ \text { Teach Module } & 6 \\ \text { Written Assign 8 x 2 } & 16 \\ \text { LabAct 4+3 + 2 } & 9 \\ \text { Personal Web Page } & 4 \\ \text { Group Web Page } & 15 \\ \text { Summary/ Thnx/Bonus } & 3 \\ \text { Moderator } & 5 \\ \text { Submit Exam Question } & 1 \\ \text { Web Demo } & 3.3 \\ \text { Grand Total = } \quad \text { 109.3\% }\end{array}$

The interesting part is that the total is more than $100 \%$. It is close to the proverbial $110 \%$ that only athletes can achieve. There is a sizeable part of the mark that is made up of 'bonus' marks. Volunteering to be the moderator, or to do a summary, or by submitting an exam question all were worthwhile endeavors. There were also bonus marks awarded for being the photographer, and for giving special lectures.

\section{Exams:}

There were two exams, a midterm and a final. Both had a written part and a computer part. The written part was comprised of writing an essay and answering some questions that were related to design. The students were graded on writing skills as well as technically answering the question. The computer part was done as a quiz on WebCT. There were fifty multiple choice questions, with each question having five choices. This was efficient in terms of marking and getting the grades tallied; it was done automatically. I try to avoid multiple-choice, in that it does not encourage much creativity, but in dealing with a large class, one must be practical.

The logistics of having 150 students do their exams on only 25 computers, is also a bit tricky. But by having the students do the writing part first, they more or less came through the computer lab at about the right rate. It only takes a few minutes to answer fifty multiple choice, and we usually set the 'time-out' to 20 minutes. Most students could complete the multiple-choice in about fifteen minutes. Students were given plenty of time for the writing; we typically gave them two hours.

I told the students that if they missed the exam, they missed the marks. But I softened up a bit and let some students write a day or so later, it they had a legitimate excuse, and if they emailed me and requested the rewrite in a professional manner.

With WebCT, one could write the quiz on any computer that is connected to the internet. A couple of years ago we allowed this, but ran into some cheating, so now we only allow the students to write the exams on designated computers, and the exam is pass-worded. 


\section{Crib Sheet:}

I have always believed that individual crib sheets encourage good study habits, and discourage memorization. So I allow them in all my exams, but some conditions apply:

$>$ Must be done in your own hand

$>$ No windows, doors, flaps, etc.

$>$ No photocopied sections

$>8.5 \times 11$ inches

Students are strongly encouraged to submit exam questions. If the question is used on the exam, one mark is awarded to that student. I put the students name in small print beside the question. I think this works well for a couple of reasons. The students take more 'ownership' of the course and are extremely proud to see their name beside a question. And the second reason is that students keep the process fresh with questions that are interesting and innovative. The third reason that students like submitting questions, is that if they submit a question, there is a good chance they will know the answer.

\section{Topics}

Some topics covered by the course:

$>$ Time Management

$>$ Proposals, Tenders, Specs

$>$ Case Studies of Engineering problems and designs, farming, education

$>$ Grammar \& Writing, noun verb agreement, parallel structure, letters, email

$>$ Report Writing

$>$ Running a Meeting, minutes

$>$ Oral Presentations

\section{Class Anatomy}

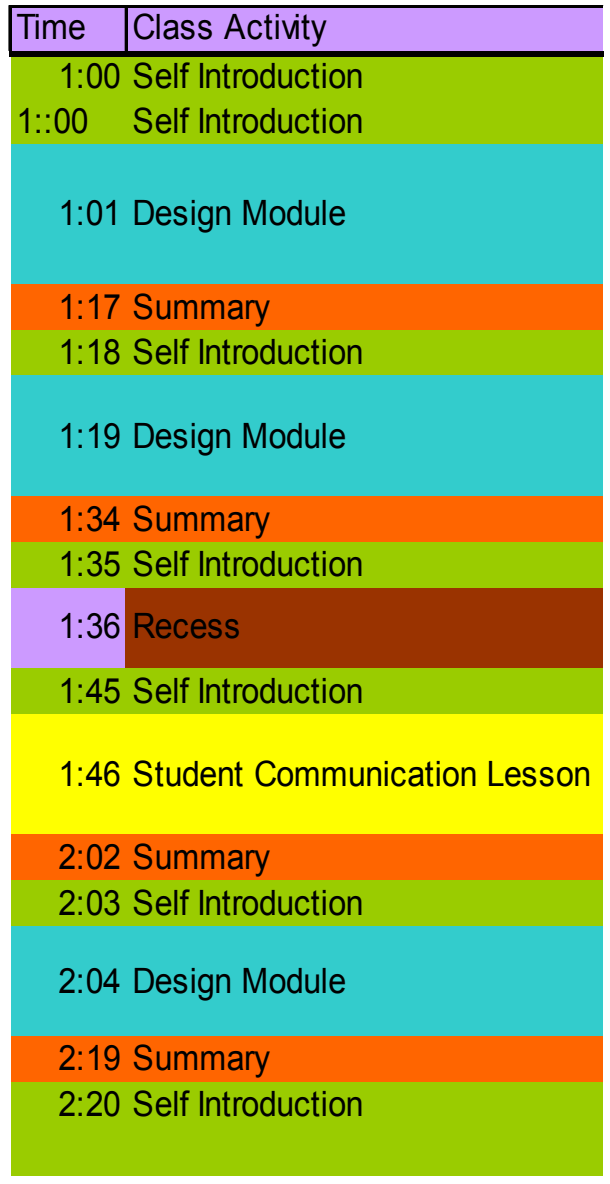

Figure 1 Class Anatomy

The lecture time was from 1:00 to 2:20 and was broken up into four modules (Fig 1.), with a short recess at the midpoint. I would typically teach the first and second module and then during recess a student group would prepare to do the third module. I would finish with the last module. The whole affair was under the direct control of the moderator. The moderator's main job was to keep things moving - on time; and I must say that the student moderators did a fantastic job.

The modules were interspersed with something called self introductions. I made a program with an Excel ${ }^{\mathrm{TM}}$ macro to randomly select a student. Student names would flash across the big screen 
and would finally stop on a name that had not been previously selected. This was all done by the moderator who would then call that student to the front. After the intro the moderator would enter the mark that he thought was appropriate. If a student was absent, a special mark was entered to indicate that their opportunity had been lost. The program also automatically recorded the date.

The main points of the introduction:

$>$ Worth $4 \%$ of your final grademarked out of 10

$>$ Your name is selected randomly by a computer program

$>$ Come to front and introduce yourself

$>$ Clearly state name with a hook or a handle, so that we can remember it.

$>$ Enthusiasm and Energy

$>$ Eye contact, work the whole audience

$>3$ things about yourself, -- hobby, pets, hometown,

$>1$ minute introduction of yourself

$>$ You will NOT be given any warning

$>$ Must come to the front of the room, and introduce yourself by giving us your name, where you are from, your hobbies, and a crutch to remember your name etc. You can be creative here, and perhaps even humorous.

$>$ Get 1 mark for just coming to the front, and giving your name,

$>$ If you aren't present when your name is called -- too bad

There were also introductions of student presentations done by a student prearranged with the moderator:
At the beginning of class, the moderator asked a person at random to introduce the student teaching presentation. This student will have only the time during class and the break to find out about the presentation, and to give a 1 min Introduction to the lesson and should include:

1. Title and people presenting

2. One or two important points to watch for in the presentation

3. Enthusiasm, energy, articulate, interesting, engaging the whole room.

\section{Student Teaching Module}

For each class, one pre-assigned group would do a 16 minute presentation on a pre-selected portion of the design text. The students were told:

$>$ Worth $6 \%$ of your final grade

$>$ Done as a group, the first one will be done by group 1 on Tuesday and it will cover Chapter 1, Engineering Design by Patrick Little

$>$ Group can use overhead, Powerpoint, blackboard, document camera,

Use one, two, or all students from the group, -- but you all get the same mark

You will be marked on :

1. Energy and enthusiasm, -- not reading

2. Material well researched

3. Material well organized, intro, body, summary

4. Professional attire, all members participated and appeared interested through the entire presentation

5. Presentation engaging; the entire room was worked; it was interesting, and I learned something 
All the groups used power point, and many had some novel presentation gimmicks.

\section{Teams:}

Last year I had 150 students that I broke up into 24 groups randomly by using a special feature of WebCT. The students were told:

$>$ You have been assigned in groups, randomly

$>$ I have gone down the class list and we have 24 groups of 5 or 6 students. (optimum number is 5)

The mark for your group web page, the group activities, and teaching will yield the same for all members in the group.

\section{Design Project}

Each year I have a different design project. One year we designed a chair, another a door, and this year I gave them a real world problem of designing a heating system for my newly built cottage:

$>$ We will be designing a hydronic, radiant floor heating system -each group will be designing a heating system, and all the pertinent documentation will go on the group web page -- there will NOT be a final report

Note: I got the students to mark each others project. They asked brutal questions and were not afraid to embarrass the other teams with questions of which they knew the answer. I made up a large matrix, in which every group entered a mark for all the other groups.

\section{Computer Activities:}

$>$ Your TA will give you a small lecture about the topic of the day, and you will then do a short 5 quest. Quiz.

$>\quad$ virtual meeting, personal web page, group web page,

$>$ WebCt, Internet, Computer Resources on Campus

$>$ Java, C, MatLab

$>$ Transfering files, FTP, Telnet

The objective was: 'To have you feel comfortable in using a computer.'

\section{The Moderator:}

On the first day of class I explained the function of the moderator:

$>$ For each class I will get one student to volunteer to be a moderator for that class

$>$ It is worth $5 \%$

$>$ Conferences often have moderators for different sessions to make sure that the speakers stay on schedule, and that everything runs smoothly

$>$ It is an important function

$>$ Just before class I will ask for a volunteer, first come - first serve.

$\mathrm{He} / \mathrm{she}$ will sit in the first row, or on stage near the overhead projector.

\section{Summary}

The moderator will select a student before the module to do a summary, at the end of the module the moderator will ask this person to come down and give a summary. The three things I will mark on are:

1. The main point or theme of the module, (delivered with enthusiasm - pretend that it was interesting)

2. Two good things - they were done right

3. Two things that could be improved (Ex Louder, slower)

The students critiqued and summarized each module, including the 
ones I did. I must say that they did a wonderful job in always finding a couple of things that I was not doing right - and that is exactly what I wanted them to do.

\section{The Gong:}

During the student presentations I would 'gong' them at any time. This interruption was just a brief moment I took with the class to critique the ongoing presentation. The fundamental question was: "How could this presentation be better?"

\section{Labs}

The labs were from $2: 30$ to $4: 20$ on Thursday. The class was broken into thirds of 50 students each. There were three concurrent sessions: a writing session, a computer session done in a computer lab, and a design activity. I had a TA for the writing session in a separate classroom, and a TA for instructing the computer lab. After 35 min. the students would rotate and go to a new session. See Figure 2.

The writing sessions had a writing assignment for each week and consisted of essays, memos, letters, and specifications.

The computer session was already described, and at the end of each session there was a short quiz. This was done for a couple of reasons. First, it made sure the students were paying attention, and secondly, it gave the student practice in the procedure that they would use to write the midterm and final computer exams.

\begin{tabular}{|r|l|l|l|}
\hline \multicolumn{1}{|l|}{ Time } & Computer489 & Writing & Group Activity \\
\hline 2:30 & Third 1 & Third 2 & Third 3 \\
\hline 3:05 & Third 3 & Third 1 & Third 2 \\
\hline 3:40 & Third 2 & Third 3 & Third 1 \\
\hline 4:10 & Finished -- possible group meeting & \\
\hline
\end{tabular}

Figure 2 Lab schedule
The design activity could be in designing and building a paper airplane that would fly the furthest. It could be to design and build paper columns that could hold the most weight. It might be to brainstorm the most uses for a toothpick or it might be to estimate the number of jellybeans in a jar. This was a competitive exercise and the team that was first would be awarded $4 \%$, second $3 \%$ and third $2 \%$.

The first few years I did this I awarded only the first team marks, but I found that the same team would keep winning, week after week. So I spread the marks around a bit by awarding marks to the first, second and third place.

Another lab activity was minidebates. I got someone in from the $\mathrm{U}$ of $\mathrm{R}$ debating club to demonstrate a real debate, and then got them to judge the student teams debating. For this lab activity, I got a volunteer student for moderating and time keeping.

Another activity done for the labs was to demonstrate a communication principle in which the message gets corrupted. A typed message was given to one student in the team, and then the message was relayed across the classroom through five other members. The team that first got the exact message, was awarded first place.

\section{Guest lecture:}

Two or three guest lectures were brought in or students volunteered to give a lecture (16 min) to the class on a design. But even the external lectures were under the constraints of the schedule and the scrutiny of student giving the summary. 


\section{Methods and Observations}

ENGG 113 was a course that was designed to have students learn about engineering and designing. This task was made even more difficult by having a large number of students.

\section{What Works:}

The moderator concept works surprisingly well. In all the years I have been teaching this course, I have only had a couple of days in which the moderator was not up to the task. I have been moderately surprised at how well the moderator has control of such a large class - even to the point of keeping the whispering down in the back.

Assigning a photographer to take digital pictures and post them on the web kept the class as a unit, and also helped all of us remember names. The strategy behind all the student volunteer activities, was to keep the students involved in the class. The short $16 \mathrm{~min}$ modules and the breaks in the lab, kept everything moving and changing and hopefully not boring.

The self introductions served a couple of purposes. It broke the ice for many who had no oral presentation skills, and it also gave everyone a chance to learn the names behind the faces.

In designing we are always looking for a 'better way'. This better way can only be created by understanding the flaws. The summaries were an attempt for the students to be vigilant in seeking out the flaws, and in suggesting a better way.

The student teaching modules also served many purposes. It gave the students a chance to organize as a team, and then to practice presentation skills, all the while in actually teaching from the design text. I think this worked quite well.

The labs, or the three ringed circus, was an exhausting time for me, but I do believe that the students did learn. Some students complained that the activities were too childish, or too simple; but I think most of the students realized that these exercises were designed to give them design experiences working as a team. Some teams seemed to just snap together and would end up winning activity after activity. Other teams never 'got it'; and consequently never won any activities.

The design project was illdefined, just like in the real world. I told the class that I would answer questions that were posed, but defining the problem was a major part of the design itself. Some students were frustrated with this, but I think most of the students understood the reason for being vague.

Using WebCT was useful, and all notifications, lectures, and marks were posted. As well we did part of the midterm and final on it. Even with the use of a TA, I still found that I spent hours posting marks - but the students liked the immediate feedback they got when the marks were posted.

The random student generator program worked $\mathrm{OK}$, but it could use a little refinement. For example, I had it so that when the moderator entered the mark, the mark was in the smallest size possible so that it would not be visible to the class. On the big screen, one could still make out the mark.

The design project done as a web page and a web page demonstration worked out $\mathrm{OK}$, and I really liked the other groups marking. This really kept the interest up.

Having all groups work on the same design problem, makes things 
easier to mark, and it also creates a competitive atmosphere - "who can come up with the best design?"

The texts for the class were "Engineering Design" by Patrick Little et al and for the communication part I assigned "Checkmate, A Writing Reference for Canadians" by Joanne Buckley. Hopefully this would serve as a reference for the entire career of the student.

The course covered a wide assortment of topics that were related to design. We covered time management, project management, estimating, a little risk management, debating, active listening, persuasive writing and introduced engineering subjects such as information theory and control theory as well as thermodynamics. Obviously none of these could be taken in any depth; but the idea was to 'wet their appetites' and to get them excited about designing and engineering.

\section{Suggestions:}

This year I came up with the idea that there should be a seating plan. The teams should be sitting together, and it would be much easier for me to identify students. I haven't done this yet, but I think this would be a good innovation.

The other perennial problem is the team member that does not fit. Every year there are complaints about team members that don't show up, that don't share in the work, and in some cases destroy the moral of the team. I like the idea of teams having the ability to fire a team member - but I am a bit afraid of this.

\section{Conclusions}

Design courses are difficult to teach and are extremely time consuming. However if the course is designed properly, it can be a rewarding experience for both the professor and the student. 